\title{
Factors promoting resilience among Mexican immigrant women in the United States: Applying a positive deviance approach
}

\section{Factores que promueven la resiliencia entre las mujeres inmigrantes mexicanas en los Estados Unidos: Aplicación de un enfoque de desviación positiva}

Received on August 3, 2017.

Accepted on December 8, 2017.

Published on March 12, 2018.

${ }^{*}$ Corresponding author: Maria Sajquim de Torres, e-mail: mdtorres6@miners.utep.edu
This work is licensed under a Creative Commons Attribution-NonCommercial 4.0 International License.
Maria Sajquim de Torres ${ }^{\text {a* }}$ (i) https://orcid.org/0000-0002-1613-6696 Mark Lusk ${ }^{b}$ (D) https://orcid.org/0000-0003-1861-4476

${ }^{a}$ University of Texas at El Paso, Center for Interdisciplinary Health Research and Evaluation, United States of America, e-mail: mdtorres6@miners.utep.edu

${ }^{\mathrm{b}}$ University of Texas at El Paso, United States of America, e-mail:mwlusk@utep.edu

\section{Abstract}

This research project used a positive deviance approach to identify Mexican immigrant women (MIW) who have experienced great stress and who have positive mental health indicators in order to determine the factors behind their resilience and coping skills. Signposts, strengths and resources contributing to positive mental health are identified and described. The resilience of participants in this study emerged as a very dynamic phenomenon. A series of internal assets helped these women find meaning, purpose and build resilience. Social networks, families, positive attitudes, and purposeful behaviors determine the strengths and well-being of this group. This may be the first exploration of the mental health assets of MIW. Although the purposive sample in the study limits the generalization of its results, the specificity of its population is a clear point of comparison and reference. The study has implications for the design of health promotion interventions with individuals of Mexican shared ancestry.

Keywords: immigrant women, mental health, assets perspective, positive deviance.

\section{Resumen}

Esta investigación utilizó un enfoque de desviación positiva para identificar mujeres inmigrantes mexicanas (MIM) que han experimentado un gran estrés y que tienen indicadores positivos de salud mental con el fin de determinar los facto-

CITATION: Sajquim de Torres, M. \& Lusk, M. (2018). Factors promoting resilience among Mexican immigrant women in the United States: Applying a positive deviance approach [Factores que promueven la resiliencia entre las mujeres inmigrantes mexicanas en los Estados Unidos: Aplicación de un enfoque de desviación positiva]. Estudios Fronterizos, 19, e005. http://doi.org/10.21670/ ref.1805005 
res detrás de su capacidad de adaptación. Para tal efecto se identifican y describen los indicadores, fortalezas y recursos que contribuyen a una salud mental positiva. Como resultado se identificó que la resiliencia de las participantes en este estudio emergió como un fenómeno muy dinámico. Las mujeres estudiadas mostraron activos internos que las ayudan a encontrar significado, propósito y desarrollar resiliencia. De manera específica, las redes sociales, familias, actitudes positivas y conductas determinan las fortalezas y el bienestar de este grupo. Esta puede ser la primera exploración de los activos de salud mental de мıм, y si bien la muestra intencional limita la generalización de sus resultados, la especificidad de su población es un punto claro de comparación y referencia, por lo que el estudio es una contribución para el diseño de intervenciones de promoción de la salud con individuos de ascendencia mexicana.

Palabras claves: mujeres migrantes, salud mental, activos para la salud, desviación positiva.

\section{Introduction}

Research has suggested that immigrant groups in the United States are at high risk of developing psychological problems due to the adverse conditions they confront. Immigrant women are believed to have a particular vulnerability to developing mental illnesses (Fellmeth, Fazel \& Plugge, 2017). Studies following a deficit based model, propose that women, in particular, experience a significant number of critical situations that may be detrimental to their health and well-being. Although this belief is widespread, most studies on their mental focus on the prevalence and associated factors for mental disorders at the peri and post-natal states (mostly depression and anxiety) without necessarily considering other life stages or the multitude of stressors before, during and after migration which exacerbate risks for this already vulnerable group.

Earlier studies that examined the mental health of Mexican immigrant women (MIW) documented high incidence and prevalence of depressive symptoms and identified low socioeconomic status, lack of social supports, and recent traumatic events as factors that contribute to poor mental health indicators in this population (Salgado de Snyder, 1987; Vega, Kolody, Valle \& Hough, 1986; Vega, Kolody \& Valle, 1986). Recent studies continue reporting a high prevalence of depressive symptoms among Mexican immigrant women and identify additional factors that affect their mental health (Fox \& Kim-Godwin, 2011; Garcini et al., 2016; Ornelas \& Perreira, 2011). These include: an extended time of residence in the USA, ethnic discrimination and antiimmigrant sentiments, threats of deportation, financial insecurity, loss of connections with family and friends in their country of origin, experiences of trauma, loss and adversity, language limitations, stress due to the inability to find employment, feelings of not fitting into a new culture, lack of familiarity with new environment, conflict between traditional and new customs and values, feelings of shame, and not participating in the decision to migrate. In contrast, in this research migrants experienced high stress, but their mental health indicators were not poor. Indeed, they exhibited resilience and strong coping skills. We explore the resilience of Mexican immigrant women and highlight factors associated with this trait using a positive deviance (PD) approach. In this methodology, it is reasoned that the solutions to many health and community problems already exist and can be identified by examining those segments of the 
population that have surmounted the problem (i.e. they have deviated positively from an expected negative outcome). In many common problems, some individuals have devised simple and lasting solutions to their difficulties. Positive deviance seeks to uncover and replicate these solutions (Baxter, Taylor, Kellar \& Lawton, 2015; Pascale, Sternin \& Sternin, 2010; Singhal, 2013). The purposes of this study were to identify immigrant women who had not succumbed to the adversity encountered in their lives and to uncover the factors behind this paradoxical outcome. An asset based approach helped uncover assets that Mexican immigrant women possess which contribute to their mental health. In addition to emphasizing the assets of individuals and groups, this approach avoids the risks of labeling identified problems as negative byproducts of the individual's or group's culture.

\section{Mental Health Among Mexican Immigrants}

Most research on the mental health of Mexican immigrants does not differentiate results by gender. With this limitation, contrasting results characterize research on the mental health of Mexican immigrants. One line of results emphasizes their positive health and the protective features of ethnicity and culture as evidenced by the Hispanic and Mexican immigrant health paradox. This refers to the counterintuitive finding that despite high risks associated with poverty, discrimination and poor healthcare access, Hispanic immigrants have far better health and mental health indicators than nonHispanic Whites (Ruiz, Steffen \& Smith, 2013). For example, data from 6776 individuals in the National Comorbidity Survey Replication and the National Latino and Asian American Study found that Mexican immigrants had lower rates of depression anxiety, and substance use disorders than the general population (Alegria et al., 2008). Positive mental health in the group was attributed to the protective effects of foreign nativity, cultural practices in the country of origin, and the perception of neighborhood safety in the destination country (Alegría et al., 2008, p. 365). Contrasting findings emphasize the high rates of mental disorder among Hispanic immigrants. For example, an article based on data from the Multiethnic National Study of Atherosclerosis, $(\mathrm{N}=6813)^{1}$ found very high rates of depression, anger, and anxiety disorders among Mexican immigrants. This study did not reach a clear conclusion on the factors that negatively influenced the mental health of immigrants, but observed that a lengthy residence in the USA is linked to acculturation (Casillas et al., 2012, p. 1728).

Given these contrasting findings, scholars have questioned the theoretical basis and the methodological approach of studies on immigrants. Theoretically, a major drawback in these studies is the excessive focus on culture as if were the most important determinant of health, without consideration of other contextual social and historical processes affecting individuals (Abraído-Lanza, Armbrister, Flórez \& Aguirre, 2006; Torres \& Wallace, 2013; Viruell-Fuentes, Miranda \& Abdulrahim, 2012).

The epidemiological risk factor approach and its assumptions on the linear association between culture and health has generated criticism throughout the years (e.g., Palloni \& Morenoff, 2001). Also, the biomedical perspective and emphasis on risk and protective factors as determinants of disease and the lack of consideration of ecological and

${ }^{1} \mathrm{~N}=$ Total sample of participants in the studio. 
societal contexts of health and disease have received criticism (Shy, 1997). In relation to the mental health of immigrants, an example of the shortcomings in these studies is the lack of consideration of the complex sociocultural and historic processes that push immigrants out of their countries, the adverse experiences during the migration, and adaptation to new living conditions (Chirkov, 2009; Sajquim-Torres, 1999).

Recent research has now begun to address the theoretical limitations of conflating culture with adverse outcomes in mental health (Torres \& Wallace, 2013; ViruellFuentes et al., 2012). Nonetheless, studies still implicitly neglect or minimize the role of knowledge, attitudes and behaviors or any other influence of the immigrants that contribute to their positive health upon arrival and over the long term.

Given that Mexican immigrants can spend an extended period of years without their mental health being adversely affected, it is important to examine the sources of the initial resilience of immigrants and to identify factors that may prevent the erosion of their health (Breslau et al., 2006; Franzini, Ribble \& Keddie, 2001; Morales, Lara, Kington, Valdez \& Escarce, 2002; Ruiz et al., 2013). Determining the sources of their resilience calls for the consideration of alternative perspectives that can offer additional information for a broader comprehension of the health of this group.

Over the past two decades, increasing attention has been given to resilience and its link to social and cultural factors. Prior to the emergence of this trend, resilience had often been seen primarily as a psychological trait, one that is within the individual as a result of personal development and individual personality (Ungar, 2008). In contrast, it has been argued that resilience, a person's ability to confront and overcome challenges and adversity, is rooted in one's social ecology, which includes social networks, kinship groups, community, and cultural resources (Ungar, 2013). By broadening the concept of resilience in this way, it diminishes the tendency to blame people for the way in which they confront hardship, trauma, or adversity. It also recognizes that elements of a person's cultural context, including their embeddedness in families and social networks can have a powerful protective effect, particularly in the face of adversity or traumas, such as is experienced by many migrants (Ai, Aisenberg, Weiss \& Salazar, 2014; Ungar, 2013; Ungar \& Liebenberg, 2011).

To complement this trend, there has been an emerging line of research on Latino migrants that has documented this group's positive adaptations to stress, adversity and trauma (Farley, Galves, Dickinson \& Diaz, 2005; Lusk \& Galindo, 2017; Marsiglia, Kulis, García \& Bermudez-Parsai, 2011). The research by Farley, Galvez, Dickinson and Diaz found that Mexican immigrants had significantly better mental health functioning than non-Hispanic white Americans and citizens of Mexico. They specifically observed that stress was mediated by humor, positive reframing, religion, and acceptance-effective cultural adaptations to adversity (Farley et al., 2005). Flores-Yeffal documented the important protective role of migration trust networks in easing the adaptation of Mexican migrants to the host society. She found that these social networks are a powerful protective factor by providing social supports, building social capital, preserving cultural integrity, thereby helping to overcome adversity (Flores-Yeffal, 2013).

Research with refugees and forced migrants from Mexico has also documented resilience and the role of culture in meeting the challenges of migration. In a study of migrants who had fled violence and criminal victimization in Mexico, Lusk and McCallister (2015) found that while many of the migrants experienced signs and symptoms of depression and post-traumatic stress, they also exhibited positive adaptation based on their use of cultural values and traditions. Another study 
of refugees documented that many forced migrants from Mexico have experienced profound trauma and violence including torture, rape and abuse and yet maintained hope in the face of adversity and drew meaning from family and faith in persevering and were able to mediate their depression by becoming deeply involved in their culture and community (Chavez-Baray, Lusk \& Sanchez, 2015; Lusk, McCallister \& Villalobos, 2013). In a follow-up study, Lusk and Chavez-Baray (2017) explored resilience and the role of culture among forced migrants and found higher than average scores on the Connor Davidson Resilience Scale and noted that participants also pointed to the role of social networks and culture as protective factors. Many had sustaining cultural values that they invoked to maintain personal integrity under adversity including deep personal friendships, community, family and faith (Lusk \& Chavez-Baray, 2017). In a project that directly aimed at identifying strengths and resilience among forced migrants from Mexico, Lusk and Galindo (2017) discovered that three core factors - hope, family and faith-were central to successful adaptations to migrant trauma and stress.

\section{Methods}

This study included the sequential collection of quantitative data with a diverse sample of Mexican women $(\mathrm{N}=100)$ and qualitative data with a smaller purposive sample $(\mathrm{n}=14)^{2}$ of positive deviants. A demographic form that requested socioeconomic data and information on adversity and the scores obtained from a scale measuring well-being produced quantitative data to screen participants and identify positive deviants. Qualitative data collected from identified PD through in-depth interviews was analyzed using content analysis.

\section{Sample and Recruitment}

Key informants in five different sites throughout the usa side of the El Paso del Norte Region helped recruit Mexican women who participated in this research $(\mathrm{N}=100)$. These women went through a screening process using the previously mentioned instruments and the following criteria: adults (18 years and older), born and raised in Mexico up to the age of 16 or older, self-identification as a Mexican immigrant woman, low socioeconomic status (determined by income at or below poverty line), living in the U.S. at least 10 years, who experience significant adverse events related or unrelated to immigration, and maintain a high level of resilience and well-being.

The well-being of participants was measured with the Flourishing Scale. This scale assesses personal functioning traits such as positive relationships, competence, and having meaning and purpose in life (Diener et al., 2010; Diener \& Ryan, 2008). The Flourishing Scale includes eight Likert scale items with values from complete agreement to complete disagreement ( 1 to 7 points each). The scale yields a score ranging from 7 to 56 with a higher score indicating a higher level of well-being; it has high reliability and validity (Cronbach Alpha .87) and is convergent with similar scales

\footnotetext{
${ }^{2} \mathrm{n}=$ Refers to a subgroup of the total number.
} 
(Diener et al., 2010). It has also demonstrated validity in assessing well-being among Hispanics (Cassaretto \& Martínez, 2017) and is suitable for use with varied age ranges (Hone, Jarden \& Schofield, 2014). The research used the Mexican Spanish version of the Flourishing Scale (escala de florecimiento).

The screening process also allowed the exploration of women's accounts of adverse events to compare them with those described in the literature and the assessment of immigration-related events such as stigma, discrimination, escaping from violence, suspended grief, and chronic illness.

\section{Results}

The initial screening of $100 \mathrm{MIW}$ provided data that evidence some of the adversity they confront and helped in the selection of positive deviants: women with the most severe and higher number of adverse events experienced and highest level of wellbeing. Table 1 includes screening data.

Table 1: Descriptive data: socio-economic and well-being results $(\mathrm{N}=100)$

\begin{tabular}{l|l|l}
\hline Living below the poverty level (for a family of 3; mean 3.27) & $72 \%$ \\
\hline No health coverage & $59 \%$ \\
\hline Unemployed & $60 \%$ \\
\hline Limited or no schooling & $35 \%$ \\
\hline Income does not meet basic needs & $63 \%$ \\
\hline Limited English skills & $74 \%$ \\
\hline No spousal support & $52 \%$ \\
\hline Lived in the U.S. more than 10 years & $85 \%$ \\
\hline Mean Flourishing Scale score & $49.97 \pm 5.15$ \\
\hline Very high well-being score & $48 \%$ \\
\hline High well-being score & $26 \%$ \\
\hline Average well-being score & $13 \%$ \\
\hline Low well-being score & $9 \%$ \\
\hline
\end{tabular}

Source: Own elaboration. 
Socioeconomic data, adverse events and well-being scores guided the selection of 14 positive deviants. Identified PD women expressed willingness to continue in the study when contacted and all agreed to be interviewed. The first author whose maternal language is Spanish and who has experience working with MIW conducted one-onone interviews after securing participant consent. Interviews of one to two hours were audiotaped with notes written during the interviews.

PD women had well-being scores ranging from 53 to 56 (very high well-being). Each one of them experienced significant hardship both related and unrelated to immigration such as violence and abuse, chronic health problems and disability, medical crises, adverse childhood events (extreme poverty, neglect, and physical and sexual abuse) and homelessness. In addition, harassment, exploitation, discrimination, poverty, and stigma were experiences for all of the chosen women. The PD group ranged in ages from 39 to 84 . The subsample included retired, self-employed, unemployed, disabled, and working women. They came from southern, central and western Mexican states and most moved from their city of origin to Ciudad Juárez, Chihuahua prior to immigrating to the United States.

\section{Qualitative Results}

The data analysis from interviews uncovered several descriptors, which were coded into three main domains: adversity, resilience and well-being. The data revealed patterns of recurring ideas, thoughts, and themes that were grouped to identify emergent themes in participant experiences. The figure 1 illustrates the themes and categories uncovered including a frame of reference for the development of resilience, the dynamic factors that generate it and other elements involved in this process.

\section{Adversity}

Adversity was a pervasive phenomenon in the lives of MIw that caused them develop a pragmatic and adaptive response. This adaptation may have resulted from confronting difficulties at an early age. Nine of the fourteen women reported childhood adversity through which they were aware of the "realidad de la vida" (reality of life). They seemed to have developed a positive disposition toward being challenged (Santos, 2014) and accepted that destiny cannot be controlled and adversity is part of life. In addition, most participants saw adversity as an opportunity to grow and learn. They felt that they had learned many valuable lessons from life's hardships and considered life to be a school in which "adversity was the teacher".

\section{Spirituality: Moving Through Adversity}

The theme of spirituality was associated with adversity, resilience, and well-being. Although eleven of the fourteen women interviewed identified as Roman Catholic, their reflections and ideas described more of a personal and profound knowledge and 
experience of the divine than traditional religious practices or activities. Spirituality emerged as a frame of reference that helped them understand and mediate hardship. Participants expressed two complementary spiritual ideas related to adversity: "providence" and "walking with God." Participants see providence as an expression of divine care that allowed them to trust that their problems were not permanent and that God was watching over them and would help them through adversity. Providence increased participants' self-confidence, self-esteem, and contentment as they developed a feeling of being privileged, blessed and loved by someone greater than them. "If one trusts God, you can stumble, but God will pick you up. I have felt it. I've felt it more than once. At those times, on that path, I felt very blessed, very spoiled by God. I feel like I am one of his children, a favorite one". Another emergent aspect of spirituality was "walking with God." Participants expressed great confidence in God and believed that they needed to do their part in solving their own problems. "Then, what happens to one who walks, who believes in God? One knows, one feels the certainty that He will get you through. It is the trust and the confidence that $\mathrm{He}$ is there and He will get you through. Then, I placed all my faith on Him. If I do my part, I will be ok, and everything will be ok".

Figure 1: Assets and strengths for the resilience of Mexican immigrant women

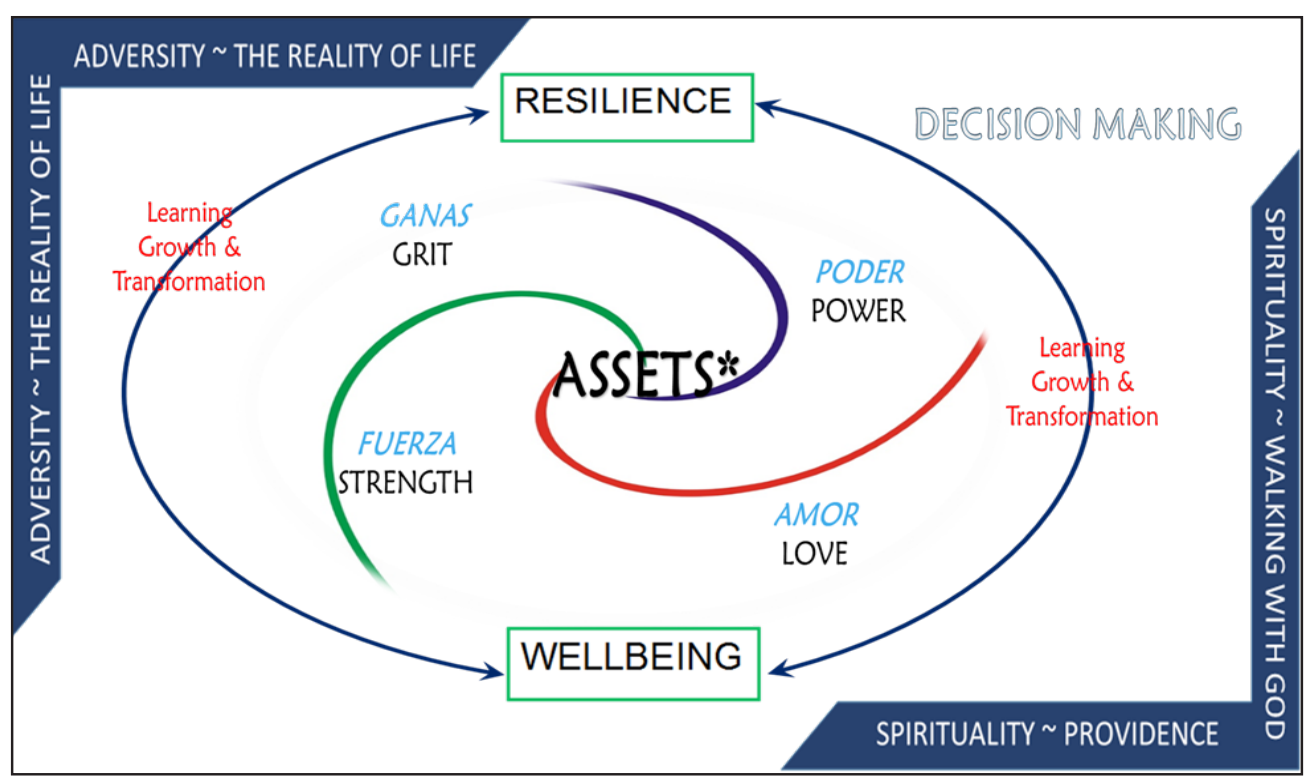

Source: Own elaboration.

\section{Resilience}

The term resilience (which has been literally translated in Spanish as resiliencia for previous studies [Grotberg, 2003; Santos, 2014] and this study) was an unknown term to all but one of women. As a result, the study addressed resilience by eliciting personal descriptions of the participants' abilities to overcome adversity. Respondents discussed 
some of the characteristics possessed by resilient women: A resilient woman is someone who is capable of achieving what she intends to: "She is 'entrona' (someone who does not back up), who sees no difficulty in anything. A person for whom 'I can't' is not an option". Another participant made the important distinction that it is not only about overcoming adversity, but continuing on a positive path. They also mentioned the importance of being objective and looking for the positive amid adversity; not dwelling "on the tragedy". After discussing resilience, they were asked what score they would give themselves in terms of their resilience. Scores ranged between 8 to +10 . Those that gave themselves a lower score explained that it resulted from their desire to be modest. Some of their reasons for the scores were explained and illustrate this phenomenon:

"I give myself a 10 because I am brave and let's move on" (P21);

"I give myself a 10 because I have kept firm" (P37);

"I give myself more than 10 because such is the level of my doggedness" (P55);

"I'd say a 10 because I am very self-sufficient, wise, and I have survived" (P79);

"A 9 because occasionally I waiver, but I have daily strength, don't get depressed, and I wake up with a goal in mind" (P35);

"I definitely will give myself a 10 because I do not stay where I fall; I get up, continue and achieve what I want. No nonsense, I earn it lawfully" (P6).

The analysis identified four markers of resilience of these women: fuerza (strength) poder (power), ganas (tenacity), and amor (love).

\section{Fuerza (Strength)}

Participants' accounts revealed a core strength that helped them offset the consequences of adversity. Most said that they felt this strength or life force was able to influence their situation through purposeful action. They mobilized this strength through a sense of responsibility, a strong will, and defining a direction for their lives. For example, when asked where that strength comes from, P68 responded:

"From living, from feeling alive, from not surrendering, from wanting to be better, from you not being a piece of paper that the wind can blow wherever it wants, from that essence that one has for living".

\section{Poder (Power)}

Power was one of the factors that allowed women to surmount adversity. They described power as the individual's personal capacity to influence an outcome and the ability to respond positively to difficulties and to actively search for information and help. It was used to carry out concrete actions to not be defeated by difficult circumstances. It entailed the conviction and resolve that no excuses or obstacles could deter them. Discussing her struggle with a cancer diagnosis, P58 commented on personal power: "When my cancer appeared [I decided] this is not going to win against me, this won't beat me. And I am going to be happy and if those living around me are very happy and I have to make happy those who live around me. I will not transmit negativity. Well, I don't know, I say that a woman has to put a $100 \%$ of herself into a difficult situation". 


\section{Ganas (Tenacity)}

Ganas refers to the desire a person has to live, fight, move on, and be well. It encompasses optimism and a future orientation, a desire to improve through planning and setting goals, conscientiously working to achieve them, and internal motivation. Factors that define ganas are giving it your best, tenacity, strong will, and perseverance. "It is having ganas and not looking back. We can. It is possible to move forward with God's help and doing your part because if we leave it all up to God... oh well, no. So, having ganas and saying I can, I can. And being optimistic and saying I can and you can, when one says I can do this, one is able to do it. It is having ganas, lots of ganas." "All the adversities or difficulties taught me that I should not depend on someone else; that I always have to be an optimist. That I shouldn't be thinking that I won't be able to, but that I will." Another participant commented: "How did I move forward? I had put on all the ganas of the world. I said this is not going to annihilate me. I have to fight".

\section{Amor (Love)}

The final element of resilience was love. In this case, love referred to valuing or loving oneself (self-esteem and self-respect) and other qualities of connection (Ryff \& Singer, 1998). In relation to love, one of the participants suggested the worst adversity, "the hammer that crushes an immigrant woman" is "el desamor" (lovelessness). El desamor was described as not having the support of family and friends, which causes women to become depressed and seek solutions where there are none. Love was thus considered critically important and was understood as both given and received (reciprocal). Participants who had experienced domestic abuse went through a process that led first to self-awareness and then to self-esteem. They described love as kindness towards others going through similar situations. All agreed that helping others was a positive adaptation to adversity and contributed to their resilience. Helping others was restorative and included working in the community as an unpaid promotora (health promoter), visiting other immigrant women in prison, advocating for workmates through a position as an union representative, promoting social justice, advocating for children and families at school, assisting counselors working with children and families at her work site, listening and advising people at work or in public and offering assistance to others experiencing loss.

\section{Assets for Resilience and Well-Being Among Mexican Immigrant Women}

\section{Internal Assets and Strengths}

Strengths are internal attributes or intrinsic assets that individuals possess which help overcome adverse events and contribute to well-being. Internal assets encompass a set of the positive attributes including attitudes, capacities, interests, thoughts, emotions, reactions, skills, or knowledge (Simmons \& Lehmann, 2013). The interviews identified several assets and strengths that foster resilience and well-being. 


\section{Not Indulging Victimhood}

All of the women categorically declared that they did not feel helpless and did not see themselves as victims. This was one of the most remarkable findings of this research.

\section{Not Being Cornered by Fear}

Another common theme was consciously deciding to be unafraid when facing adversity. Several women commented on this. While they acknowledged feeling fear, they expressed determination to not let it limit them.

\section{Getting the Best out of the Bad While Being Grateful}

Women said they grew from adversity. Participants said they looked for the positive amidst difficulties. This attitude allowed women to remain hopeful as they searched for even the smallest drop of hope to be rekindled that could help their situation and prevent feelings of defeat or failure.

\section{Finding Meaning and Purpose}

Participants identified a purpose within adversity that caused feelings of satisfaction despite their suffering. Meaning and purpose were closely related to eventual outcomes that benefited them and their children.

\section{Self-Motivation and Self-Reliance}

Participant accounts suggested that, after adversity, a woman's self-determination was responsible for her situation, feelings, and decisions.

\section{External Asset and Social Supports}

Participants identified several external assets or resources that helped them with resilience and well-being. These included community organizations, friends, and family. These assets helped them create support networks, acquire knowledge, access material and financial resources, receive services, and create formal and informal opportunities and spaces to gather.

Women sought out and utilized local organizations and services such as shelters, psychological services, medical clinics, housing agencies, health fairs, community libraries, and religious activities. They said schools are places to find useful information and support and described community assets and meeting spaces as opportunities for people to gather and promote a sense of belonging and connection. 


\section{Discussion}

In contrast to studies that have focused on the pathologies of migrants, this study used positive deviance. This approach helps gain insight into the main factors that help Mexican immigrant women maintain a positive level of mental health and overcome adversity. A key conclusion of the analysis is that poverty, exclusionist immigration laws, stigmatization and discrimination are significant sources of adversity for Mexican immigrant women in the Paso del Norte region. These factors can create pronounced hardship in this population and can put their mental health at risk and yet, the participants thrive and demonstrate resilience and well-being.

The interviews reveal that repeated exposure to adversity, coupled with the spiritual beliefs of the participants, form a frame of reference from which they develop resilience. Early and frequent adversity throughout life makes them comprehend hardship as an unavoidable, but temporary part of life. This understanding and their spiritual beliefs promote acceptance, trust, purpose, hope, meaning, and contentment-all of which are indicators of well-being. One crucial finding is that Mexican immigrant women consider most adversities as challenges to be surmounted and as opportunities to learn and to grow.

Research suggests that resilience is context dependent, expressed and promoted differently across individuals and group. This implies a need for an alternative discourse on resilience, one that recognizes contextual specificity (Davydov, Stewart, Ritchie \& Chaudieu, 2010; Ungar, 2004). For Mexican immigrant women in the U.S., the contextual understanding of resilience has been largely absent in research so we used a constructivist understanding of strengths and spirit to explore their mental health. The accounts of the participants led to an understanding of resilience as the culmination of a highly dynamic process of growth and transformation derived from experiencing adversity mediated by spirituality and the interaction of several internal and social assets. Although participants in this study were unfamiliar with the term resilience, they identified several nouns in the Spanish language to interpret this response. These words and the explanations regarding how participants overcome life's difficulties suggested four signposts of resilience for MIw: poder (personal power), fuerza (strength), ganas (tenacity), and amor (love), each of which were described in detail. The internal assets of resilient MIW are (1) ability to not indulge in victimhood, (2) determination to not let fear deter her efforts, (3) the meaning and purpose of her life, (4) weighing of the good in her life and the gratefulness derived from it, (5) eagerness to look for information and help to solve problems, and (6) self-motivation and self-reliance.

Our findings suggest that families, social networks, and values sustain the women. Parental concern for the well-being of children and the importance of advice, stories, and familial role models are a source of resilience (Cardoso \& Thompson, 2010; Perez \& Cruess, 2014; Rodriguez, Mira, Paez \& Myers, 2007). Parra-Cardona and colleagues (2006) discuss the centrality of parental duty among Mexican immigrants and have proposed that children inspire their parents to rise above adversity (Parra-Cardona et al., 2006). Participants discussed love in reference to the care, concern and the filial relationship with their children, other family members, friends, and neighbors; which embodies the duty to "Love thy neighbor as thyself." The support received from friends, family, community members, and social networks of other migrants 
was a significant external resource aiding in the resilience and well-being of the participants. Participants' comments described the importance of social connections to others, which helped them avoid loneliness and isolation and eased the many losses and adversities they endured (Smith-Morris, Morales-Campos, Castaneda, \& Turner, 2012). Human connection is central to the development of resilience (DiFulvio, 2011). Connectedness in the host country also mediates homesickness-the immigrants' nostalgia for what they left behind (Smith-Morris et al., 2012).

To illustrate, a Mayan Mexican immigrant woman was buoyed by the social connections made with peers by seeking advice, telling stories and making family connections and family support and peer role models play a role in the development of a strong ethnic identity (Casanova, 2012). This identity, rooted in the participant's Mexican and Mayan origins, helps overcome adversities encountered in the United States (Casanova, 2012). In the present study, participants' sense of identity was strengthened by making connections through recounting family stories and oral histories. Participants proudly related family tales of hard work, resourcefulness, bravery, humility, and hardship that helped them develop a sense of identity and stressed the importance of family values. One of these values, "trabajando duro" (working very hard) had particular cultural significance for participants. This value reflects commitment, community, and solidarity (Parra-Cardona et al., 2006). Participants fashioned a lifestyle and a commitment to move forward by "trabajando duro" when facing the difficulties.

Collectivism was another cultural factor linked to establishing close personal bonds beyond the family group, including social networks of fellow migrants. Collectivism is not solely a Hispanic or Mexican value, but is commonly associated with non-Western cultures and can be contrasted to the individualism of mainstream American culture (Ai et al., 2014). Despite many years of residence in the United States, engagement with social networks and kinship groups emerged as a core source of resilience among participants.

The protective role of spirituality among the immigrant women in this study is consistent with a body of literature on immigrants and other groups (Braxton et al., 2008; Connor, 2012; Koenig, 2012; Lake, 2012; Rosmarin, Wachholtz \& Ai, 2011; Smith, Webber \& DeFrain, 2013; Temane \& Wissing, 2006). Shaw, Joseph and Linley proposed that the beneficial role of spirituality and religion in mental health is generated through strong values and beliefs that enhance meaning of life, increase social support, and promote acceptance of difficulties (Shaw, Joseph \& Linley, 2005). Various studies have concluded that spirituality is important to resilience as a coping resource and that it has beneficial effects on well-being as a source of finding meaning (Beagan, Etowa \& Thomas, 2012; Viladrich \& Abraído-Lanza, 2009).

Spirituality has consistently emerged as an important contributive factor to resilience among women (Bachay \& Cingel, 1999; Banerjee \& Pyles, 2004; Dos Santos, Sukanya \& Harkins, 2009; Shaikh \& Kauppi, 2010). Spirituality is one of the most important factors identified for the resilience and well-being of women in this study. More than a coping strategy, it frames their life perspectives. The consensus about the importance of spirituality points to its importance for the resilience of women and suggests it may be more an element of gender rather than a cultural factor in resilience.

Life satisfaction has been identified as one strength that Mexican immigrant women exhibit despite the numerous difficulties they confront (Heilemann, Lee \& Kury, 2005; Parra-Cardona et al., 2006; Raffaelli \& Wiley, 2013). Previous work by Heilemann and 
colleagues suggests that life satisfaction may derive from the comparative advantage these women perceive between their life in the U.S. and their former life in Mexico (Heilemann et al., 2005). In contrast, we found the Mexican immigrant women have a sense of life satisfaction derived from positive relationships, appreciation and gratefulness for what they have, and a favorable attitude and satisfaction with life in general due to learning and growth resulting from adversity.

The results of this study highlight the positive mental health of Mexican immigrant women in the Paso del Norte region of the U.S.-Mexico Border. These results, however, do not constitute a justification for the distressing conditions these women confront in their everyday life or in any way minimize the inequalities they confront or justify inaction. The participants were resilient and have positive well-being, yet this should not detract from the fact that they experience considerable pain and suffering. They not only described their adversity, but talked about their emotional scars and their wounds. Risk factors for the development of depression or anxiety are present among such immigrants. Such risks can be mitigated by acknowledging and building the individual and collective resiliency found in this group.

\section{Strengths and Limitations}

This may be the first study that explores the assets that Mexican immigrant women that contribute to their mental health. We uncovered the frame of reference that facilitates the development of resilience, a series of attitudes displayed by these women to achieve well-being and the internal assets and external social resources that contribute to their positive mental health. The study utilized a purposive sample, thus the results may not generalize to other groups, yet the specificity of its population is a clear point of comparison and reference. By focusing on resilient women with a high level of wellbeing and their strategies to achieve this outcome, the study has implications for the design of health promotion interventions with Mexican immigrant women and other women of shared ancestry.

\section{Conclusion}

Mexican immigrant women living on the U.S. side of the U.S.-Mexico Border possess a significant number of assets that help them remain highly functional despite an extensive array of acute and ongoing adversities. This research establishes that immigrant women of Mexican origin who have lived for an extended period of time in the U.S., who confront significant health disparities, live in a highly disadvantaged socioeconomic condition, and experience significant adversities derived from their condition as immigrants can deviate positively from the negative expected outcome of poor psychological health that research has identified for this and other similar groups. Explaining what can be considered a paradoxical finding is a series of internal strengths and external social resources that the participants in this study have utilized, which allow them to develop resilience and maintain an extraordinary level of psychological and subjective well-being. The positive deviant approach used for the implementation of this study helped in determining that there are many Mexican 
immigrant women who are able to defy the odds and avoid maladaptation and mental disorder. This positive outcome was uncovered among members of a marginalized and vulnerable population attesting to the presence of unrecognized reservoirs of wisdom and agency among them that can meaningfully contribute to their mental health and well-being. ${ }^{3}$

\section{References}

Abraído-Lanza, A. F., Armbrister, A. N., Flórez, K. R. \& Aguirre, A. N. (2006). Toward a Theory-Driven Model of Acculturation in Public Health Research. American Journal of Public Health, 96(8), 1342-1346. http://doi.org/10.2105/ AJPH.2005.064980

Ai, A. L., Aisenberg, E., Weiss, S. I. \& Salazar, D. (2014) . Racial/Ethnic Identity and Subjective Physical and Mental Health of Latino Americans: An Asset Within? American Journal of Community Psychology, 53(1-2), 173-184. http://doi.org/10.1007/ s10464-014-9635-5

Alegría, M., Canino, G., Shrout, P. E., Woo, M., Duan, N., Vila, D., ... Meng, X. (2008). Prevalence of Mental Illness in Immigrant and Non-Immigrant U.S. Latino Groups. American Journal of Psychiatry, 165(3), 359-369. Retrieved from https:// ajp.psychiatryonline.org/doi/pdfplus/10.1176/appi.ajp.2007.07040704

Bachay, J. B. \& Cingel, P. A. (1999). Restructuring Resilience: Emerging Voices. Affilia, 14(2), 162-175. http://doi.org/10.1177/08861099922093581

Banerjee, M. M. \& Pyles, L. (2004). Spirituality: A Source of Resilience for African American Women in the Era of Welfare Reform. Journal of Ethnic E Cultural Diversity in Social Work, 13(2), 45-70. Retrieved from http://www.tandfonline. com/doi/abs/10.1300/J051v13n02_03\#.VIt7nSvF8qQ

Baxter, R., Taylor, N., Kellar, I. \& Lawton, R. (2015). Learning From Positively Deviant Wards to Improve Patient Safety: An Observational Study Protocol. BMJ Open, 5(12). http://doi.org/10.1136/bmjopen-2015-009650

Beagan, B. L., Etowa, J. \& Thomas, W. (2012). "With God in Our Lives He Gives Us the Strength to Carry On:" African Nova Scotian Women, Spirituality, and Racism-Related Stress. Mental Health, Religion E Culture, 15(2), 103-120. Retrieved from http://www.tandfonline.com/doi/abs/10.1080/13674676.2011.560145\#. VIt9PCvF8qQ

Braxton, N. D., Lang, D. L., Sales, J. M., Gina, M., Wingood, G. M. \& Diclemente, R. J. (2008). The Role of Spirituality in Sustaining the Psychological Well-Being of HIv-Positive Black Women. Women E Health, 46(2), 113-129. http://dx.doi. org/10.1300/J013v46n02_08

Breslau, J., Aguilar-Gaxiola, S., Kendler, K. S., Su, M., Williams, D. \& Kessler, R. C. (2006). Specifying Race-Ethnic Differences in Risk for Psychiatric Disorder in a USA National Sample. Psychological Medicine, 36(1), 57-68. http://doi. org/10.1017/S0033291705006161

\footnotetext{
${ }^{3}$ This project received exempt status from the Institutional Review Board of the University of Texas at El Pass (REF \#762673-1).
} 
Cardoso, J. B. \& Thompson, S. (2010). Common Themes of Resilience Among Latino Immigrant Families: A Systematic Review of the Literature. Families in Society: The Journal of Contemporary Social Services, 91(3), 257-265. http://doi. org/10.1606/1044-3894.4003

Casanova, S. (2012). The Stigmatization and Resilience of a Female Indigenous Mexican Immigrant. Hispanic Journal of Behavioral Sciences, 34(3), 375-403. http:// doi.org/10.1177/0739986312449584

Casillas, A., Leng, M., Liu, K., Hernandez, A., Shrager, S. \& Kanaya, A. (2012). A Long Way From Home: Comparing Mental Health Measures Between Foreign and U.S.-Born Latinos in the Multi-Ethnic Study of Atherosclerosis (MESA). Journal of Health Care for the Poor and Underserved, 23(4), 1719-1732. http://doi. org/10.1353/hpu.2012.0168

Cassaretto, M. \& Martínez, P. (2017). Validación de las escalas de bienestar, de florecimiento y afectividad. Pensamiento Psicológico, 15(1), 19-31. Retrieved from http://www.scielo.org.co/pdf/pepsi/v15n1/v15n1a02.pdf

Chavez-Baray, S., Lusk, M. \& Sanchez, S. (2015). Secuelas en la salud mental: El rol de la cultura y la resiliencia en migrantes y refugiados mexicanos en la región de El Paso del Norte. In P. Barraza, L. Torres, S. Sanchez \& H. Diaz (Eds.), Tácticas y estrategias contra la violencia de género: antología (pp. 219-237). Mexico: FONCA, EON Sociales.

Chirkov, V. (2009). Critical Psychology of Acculturation: What Do We Study and How Do We Study It, When We Investigate Acculturation? International Journal of Intercultural Relations, 33(2), 94-105. http://doi.org/10.1016/j.ijintrel.2008.12.004

Connor, P. (2012). Balm for the Soul: Immigrant Religion and Emotional Well-Being. International Migration, 50(2), 130-157. http://doi.org/10.1111/j.14682435.2010.00623.x

Davydov, D. M., Stewart, R., Ritchie, K. \& Chaudieu, I. (2010). Resilience and Mental Health. Clinical Psychology Review, 30(5), 479-495. http://doi.org/10.1016/j. cpr.2010.03.003

Diener, E. \& Ryan, K. (2008). Subjective Well-Being: A General Overview. South Africa Journal of Psychology, 39(4), 391-406.

Diener, E., Wirtz, D., Tov, W., Kim-Prieto, C., Choi, D., Oishi, S. \& Biswas-Diener, R. (2010). New Well-Being Measures: Short Scales to Assess Flourishing and Positive and Negative Feelings. Social Indicators Research, 97(2), 143-156. http://doi. org/10.1007/s11205-009-9493-y

DiFulvio, G. T. (2011). Sexual Minority Youth, Social Connection and Resilience: From Personal Struggle to Collective Identity. Social Science E Medicine, 72(10), 16111617. http://doi.org/10.1016/j.socscimed.2011.02.045

Dos Santos, C. M., Sukanya, R. \& Harkins, D. (2009). An Exploratory Study of Resilience and Coping Strategies Among Portuguese-Speaking Immigrant Women Survivors of Domestic Violence. American Journal of Psychological Research, 5(1), 81-96.

Farley, T., Galves, A., Dickinson, L. M. \& Diaz, M. de J. (2005). Stress, Coping, and Health: A Comparison of Mexican Immigrants, Mexican-Americans, and Non-Hispanic Whites. Journal of Immigrant Health, 7(3), 213-220. 
Fellmeth, G., Fazel, M. \& Plugge, E. (2017). Migration and Perinatal Mental Health in Women From Low- and Middle-Income Countries: A Systematic Review and Meta-Analysis. BJOG: An International Journal of Obstretics and Gynaecology, 124(5), 742-752.

Flores-Yeffal, N. Y. (2013). Migration-Trust Networks: Social Cohesion in Mexican us-Bound Emigration. United States of America: Texas A\&M University Press.

Fox, J. A. \& Kim-Godwin, Y. (2011). Stress and Depression Among Latina Women in Rural Southeastern North Carolina. Journal of Community Health Nursing, 28(4), 223-232.

Franzini, L., Ribble, J. C. \& Keddie, A. M. (2001). Understanding the Hispanic Paradox. Ethnicity E Disease, 11(3), 496-518.

Garcini, L. M., Murray, K. E., Zhou, A., Klonoff, E. A., Myers, M. G. \& Elder, J. (2016). Mental Health of Undocumented Immigrant Adults in the United States: A Systematic Review of Methodology and Findings. Journal of Immigrant and Refugee Studies, 14(1), 1-25.

Grotberg, E. H. (2003). Nuevas tendencias en resiliencia. In A. Melillo \& E. Suarez (Comps.), Resiliencia. Descubriendo las propias fortalezas (pp. 19-30). Buenos Aires, Argentina: Paidós. Retrieved from https://es.scribd.com/document/37390977/Grotberg

Heilemann, M. V., Lee, K. A. \& Kury, F. S. (2005). Strength Factors Among Women of Mexican Descent. Western Journal of Nursing Research, 27(8), 949-965. http://doi. org/10.1177/0193945905279777

Hone, L., Jarden, A. \& Schofield, G. (2014). Psychometric Properties of the Flourishing Scale in a New Zealand Sample. Social Indicators Research, 119(2), 1031-1045. http://doi.org/10.1007/s11205-013-0501-x

Koenig, H. G. (2012). Religion, Spirituality, and Health: The Research and Clinical Implications. International Scholarly Research Network, 2012, 278730. http://doi. org/10.5402/2012/278730

Lake, J. (2012). Spirituality and Religion in Mental Health: A Concise Review of the Evidence. Psychiatric Times, (3), 34-38.

Lusk, M. \& Chavez-Baray, S. (2017). Mental Health and the Role of Culture and Resilience in Refugees Fleeing Violence. Environmental and Social Psychology, 2(1), 1-13.

Lusk, M. \& Galindo, F. (2017). Strength and Adversity: Testimonies of the Migration. Social Development Issues, 39(1), 11-28.

Lusk, M. \& McCallister, J. (2015). Resilience and Trauma Among Mexican Refugees. In E. Moya \& S. Chavez. (Eds.), Salud, Género y Empoderamiento (pp. 89-119). Mexico: Editorial EON.

Lusk, M., McCallister, J. \& Villalobos, G. (2013). Mental Health Among Mexican Refugees Fleeing Violence and Trauma. Social Development Issues, 35(3), 1-17.

Marsiglia, F. F., Kulis, S., García, H. \& Bermudez-Parsai, M. (2011). Hopelessness, Family Stress, and Depression Among Mexican-Heritage Mothers in the Southwest. Health EO Social Work, 36(1), 7-18. Retrieved from http://hsw.oxfordjournals. org/content/36/1/7.short

Morales, L., Lara, M., Kington, R., Valdez, R. \& Escarce, J. (2002). Socioeconomic, Cultural, and Behavioral Factors Affecting Hispanic Health Outcomes. Journal of Health Care for the Poor and Underserved, 13(4), 477-503. 
Ornelas, I. J. \& Perreira, K. M. (2011). The Role of Migration in the Development of Depressive Symptoms Among Latino Immigrant Parents in the usa. Social Science and Medicine, 73(8), 1169-1177. http://doi.org/10.1016/j. socscimed.2011.07.002

Palloni, A. \& Morenoff, J. D. (2001). Interpreting the Paradoxical in the Hispanic Paradox: Demographic and Epidemiologic Approaches. Annals of the New York Academy of Sciences, 954, 140-174. http://doi.org/10.1111/j.1749-6632.2001. tb02751.x

Parra-Cardona, J. R., Bulock, L. A, Imig, D. R., Villarruel, F. A. \& Gold, S. J. (2006). "Trabajando Duro Todos los Días": Learning From the Life Experiences of Mexican-Origin Migrant Families. Family Relations, 55(3), 361-375. http://doi. org/10.1111/j.1741-3729.2006.00409.x

Pascale, R., Sternin, J. \& Sternin, M. (2010). The Power of Positive Deviance: How Unlikely Innovators Solve the World's Toughest Problems. Massachusetts, United States of America: Harvard Business Review Press.

Perez, G. K. \& Cruess, D. (2014). The Impact of Familism on Physical and Mental Health Among Hispanics in the United States. Health Psychology Review, 8(1), 95127. http://doi.org/10.1080/17437199.2011.569936

Raffaelli, M. \& Wiley, A. R. (2013). Challenges and Strengths of Immigrant Latino Families in the Rural Midwest. Journal of Family Issues, 34(3), 347-372. http:// doi.org/10.1177/0192513X11432422

Rodriguez, N., Mira, C. B., Paez, N. D. \& Myers, H. F. (2007). Exploring the Complexities of Familism and Acculturation: Central Constructs for People of Mexican Origin. American Journal of Community Psychology, 39(1-2), 61-77. http:// doi. org/10.1007/s10464-007-9090-7

Rosmarin, D. H., Wachholtz, A. \& Ai, A. (2011). Beyond Descriptive Research: Advancing the Study of Spirituality and Health. Journal of Behavioral Medicine, 34(6), 409-413. http://doi.org/10.1007/s10865-011-9370-4

Ruiz, J. M., Steffen, P. \& Smith, T. B. (2013). Hispanic Mortality Paradox: A Systematic Review and Meta-Analysis of the Longitudinal Literature. American Journal of Public Health, 103(3), 52-60. http://doi.org/10.2105/AJPH.2012.301103

Ryff, C. D. \& Singer, B. (1998). The Contours of Positive Human Health. Psychological Inquiry, 9(1), 1-28.

Sajquim-Torres, M. (1999). Hay que Seguir Adelante: Stress, Trauma and Mental Health Among Maya Immigrants in the United States (Unpublished M.A. Thesis). United Sates of America: Northern Arizona University.

Salgado de Snyder, N. (1987). Factors Associated With Acculturative Stress and Depression Among Mexican Women. Psychology of Women Quarterly, 11(4), 475-488.

Santos, R. (2014). Levantarse y luchar. Mexico: Penguin Random House.

Shaikh, A. \& Kauppi, C. (2010). Coping Strategies as a Manifestation of Resilience in the Face of Postpartum Depression: Experiences of Women in Northern Ontario. International Journal of Interdisciplinary Social Sciences, 5(6), 261-273. Retrieved from http://www.iji.cgpublisher.com/product/pub.88/prod.1187

Shaw, A., Joseph, S. \& Linley, P. A. (2005). Religion, Spirituality, and Posttraumatic Growth: A Systematic Review. Mental Health, Religion $\mathcal{E}$ Culture, 8(1), 1-11. http://doi.org/10.1080/1367467032000157981 
Shy, C. M. (1997). The Failure of Academic Epidemiology: Witness for the Prosecution. American Journal of Epidemiology, 145(6), 479-484. https://doi.org/10.1093/ oxfordjournals.aje.a009133

Simmons, C. A. \& Lehmann, P. (2013). Strengths and Psychotherapy. In P. Lehmann (Ed.), Tools for Strength Based Assessment and Evaluation (pp. 1-17). New York, United States of America: Springer.

Singhal, A. (2013). The Value of Positive Deviations. Monthly Developments Magazine, $17-20$.

Smith-Morris, C., Morales-Campos, D., Castaneda, E. A. \& Turner, M. (2012). An Anthropology of Familism: On Narratives and Description of Mexican/Immigrants. Hispanic Journal of Behavioral Sciences, 35(1), 35-60.

Smith, L., Webber, R. \& DeFrain, J. (2013). Spiritual Well-Being and its Relationship to Resilience in Young People: A Mixed Methods Case Study. SAGE Open, 3(2). http://doi.org/10.1177/2158244013485582

Temane, Q. M. \& Wissing, M. P. (2006). The Role of Spirituality as a Mediator for Psychological Well-Being Across Different Contexts. South African Journal of Psychology, 36(3), 582-597. http://doi.org/10.1177/008124630603600309

Torres, J. M. \& Wallace, S. P. (2013). Migration Circumstances, Psychological Distress, and Self-Rated Physical Health for Latino Immigrants in the United States. American Journal of Public Health, 103(9), 1619-1627. http://doi.org/10.2105/ AJPH.2012.301195

Ungar, M. (2004). A Constructionist Discourse on Resilience: Multiple Contexts, Multiple Realities Among At-Risk Children and Youth. Youth $\mathcal{E}^{2}$ Society, 35(3), 341365. http://doi.org/10.1177/0044118X03257030

Ungar, M. (2008). Resilience Across Cultures. British Journal of Social Work, 38(2), 218235. http://doi.org/10.1093/bjsw/bcl343

Ungar, M. (2013). Resilience, Trauma, Context, and Culture. Trauma, Violence, E Abuse, 14(3), 255-266. http://doi.org/10.1177/1524838013487805

Ungar, M. \& Liebenberg, L. (2011). Assessing Resilience Across Cultures Using Mixed Methods: Construction of the Child and Youth Resilience Measure. Journal of Mixed Methods Research, 5(2), 126-149.

Vega, W., Kolody, B. \& Valle, J. R. (1986). The Relationship of Marital Status, Confidant Support, and Depression Among Mexican Immigrant Women. Journal of Marriage and Family, 48(3), 597-605. Retrieved from http://www.jstor.org/stable/pdfplus / 352046.pdf?\&acceptTC=true\&jpdConfirm=true

Vega, W., Kolody, B., Valle, R. \& Hough, R. (1986). Depressive Symptoms and Their Correlates Among Immigrant Mexican Women in the United States. Social Science and Medicine, 22(6), 645-652.

Viladrich, A. \& Abraído-Lanza, A. F. (2009). Religion and Mental Health Among Minorities. In S. Loue \& M. Sajatovic (Eds.), Determinants of Minority Mental Health and Wellness (pp. 149-174). http://doi.org/10.1007/978-0-387-75659-2

Viruell-Fuentes, E. A., Miranda, P.Y. \& Abdulrahim, S. (2012). More Than Culture: Structural Racism, Intersectionality Theory, and Immigrant Health. Social Science and Medicine, 75(12), 2099-2106. http://doi.org/10.1016/j.socscimed.2011.12.037 
Maria Sajquim de Torres

Guatemalan-American. Research associate in the Center for Interdisciplinary Health Research and Evaluation at the University of Texas at El Paso (UTEP). Ph.D. in interdisciplinary health sciences from UTEP. M. A. in Anthropology from Northen Arizona University (NAU). B.S. in Psychology from the Universidad de San Carlos de Guatemala. She is also the current director for the El Paso Branch of the Living Lab Center for Dialogue and Transformation Borderlands Mexico-usa. Research lines: immigration, culture and mental health, resilience, asset approaches to health, positive deviance and mixed methods research. Recent publication: Sajquim de Torres, M. (2016). Becoming Resilient: A Positive Deviance Inquiry Into the Resilience of Mexican Immigrant Women. United States of America: University of Texas at El Paso.

\section{Mark Lusk}

American. Professor of social work at the University of Texas at El Paso. Dr. Lusk was a Fulbright Scholar at the Pontificia Universidad Católica del Perú and a Fulbright Research Scholar at the Pontificia Universidade Católica do Rio de Janeiro. He has also been a visiting professor at the Universidad de Costa Rica and the University of Guyana. He has worked as a consultant on projects funded by the U.S. Agency for International Development, U.S. Department of State, Ford Foundation and the Interamerican Development Bank. Research lines: migration, resilience, trauma, and international social work. Recent publication: Chavez, S., Lusk, M. \& Sanchez, S. (2015). Secuelas en la salud mental: el rol de la cultura y la resiliencia en migrantes y refugiados mexicanos en la región de El Paso del Norte. In. P. Barraza, L. Torres, S. Sanchez \& Diaz, H. (Eds.). Tácticas y estrategias contra la violencia de género: Antología. Mexico: FONCA, EON Sociales. 